\title{
Right Ventricular Diastolic Dysfunction in the Postoperative Period of Tetralogy of Fallot
}

\author{
Silvia Meyer Cardoso, Nelson Itiro Miyague \\ Curitiba, PR - Brazil
}

\begin{abstract}
Objective - To assess right ventricular diastolic function in the intermediate postoperative period of repair of tetralogy of Fallot.

Methods - We carried out a case-control study with 60 patients divided into 2 groups as follows: 1) group I30 patients who had undergone repair of tetralogy of Fallot and 2) group II - 30 healthy children. The 2 groups were paired for age, sex, and body surface. The flows in the pulmonary and tricuspid valves were analyzed with Doppler echocardiography. The presence of anterograde flow at the end of diastole in the pulmonary artery defined restrictive right ventricular physiology. Surgical, radiological, electrocardiographic, and echocardiographic variables were analized in the group I.
\end{abstract}

Results - The velocity of the A wave and the E/A ratio for the tricuspid valve showed significant differences between the groups. Cases with $E / A<1.30$ predominated in inspiration (group I - 19/30, and group II - 5/30). The duration of the QRS complex on the electrocardiogram was significantly increased in patients with $E / A<1.30$. Nineteen $(63.3 \%)$ patients had restrictive right ventricular physiology, which had a longer postoperative period, longer duration of the QRS complex, and a lower E/A ratio in inspiration. The surgical and radiological variables showed no statistical difference.

Conclusion - Restrictive right ventricular physiology was detected on the intermediate follow-up of most patients undergoing repair of tetralogy of Fallot. The postoperative period and QRS duration were increased in patients with impairment in diastolic function.

Keywords: congenital heart disease, tetralogy of Fallot, diastolic function

Hospital Infantil Pequeno Príncipe e Hospital de Clínica da Universidade Federal do Paraná

Mailing address: Nelson Itiro Miyague - Serviço de Cardiologia Pediátrica Hospital Infantil Pequeno Príncipe - Rua Vivian Stec Toledo, 70 - 82300-740 Curitiba, PR - E-mail: nmiyague@cardiol.br

English version by Stela Maris C. e Gandour
Studies in the literature have shown that electrocardiographic, radiological, and clinical alterations may be related to the prognosis of the patient undergoing total repair of tetralogy of Fallot ${ }^{1-9}$.

Biventricular systolic function is preserved in most patients ${ }^{2-4}$. However, right ventricular diastolic function has been recently observed to show signs of impairment with a diverse behavior in different phases of the postoperative follow-up ${ }^{24}$.

This way, restrictive right ventricular physiology may be related to a complicated evolution in the early postoperative period ${ }^{2-4,6}$, but on the other hand, to a more favorable course in the late postoperative period ${ }^{3}$.

This study aimed to assess the clinical, electrocardiographic, and radiological factors related to right ventricular diastolic dysfunction in the intermediate postoperative period of the repair of tetralogy of Fallot.

\section{Methods}

We carried out a case-control study with 60 children with a mean age of $104.64 \pm 45.65$ months (24 to 197 months), who were seen at the Hospital Infantil Pequeno Príncipe from June 1 st to October 30th, 2000. The female/male ratio was $0.87(28 / 32)$.

The children were divided into 2 groups: 1 ) group I comprising 30 patients who had undergone correction of the tetralogy of Fallot, with a mean age of $35.4 \pm 25.7$ months (6 to 108 months), and a mean postoperative follow-up of $77.5 \pm 38$ months ( 20 to 143 months), and who were sequentially selected at the pediatric cardiology outpatient care unit; 2) group II - comprising 30 healthy children, who were selected at the pediatric cardiology and orthopedics outpatient care units with normal clinical, electrocardiographic, and echocardiographic examinations, with no systemic disease, dehydration or syndromes, and who were paired with group I patients for age, sex, and body surface.

Patients with the following characteristics were excluded from the study: genetic or chromosomal syndromes, hypoplasia or absence of confluence of the pulmonary bran- 
ches in the preoperative period, association with atrioventricular septal defect or agenesis of the pulmonary valve, significant residual ventricular septal defect, residual gradient in the right ventricular outflow tract greater than 40 mmHg on Doppler echocardiography, significant insufficiency of the atrioventricular valves, and presence of the connection tube from the right ventricle to the pulmonary artery.

All patients underwent total repair of the tetralogy of Fallot at the same service and by the same surgeon. The defect was repaired through right ventriculotomy, with widening of the outflow tract, a transannular patch, and closure of the ventricular septal defect, using a prosthetic tissue of polytetrafluoroethylene.

All children studied underwent complete clinical examination, 12-lead electrocardiography at rest, chest radiography, and transthoracic echocardiography, performed with the Hewlett Packard sonus 1000 and sonus 1800 devices. The parents of the patients provided written consent for the examinations, and the project was approved by the Committee on Ethics of our hospital.

The following variables were obtained on Doppler echocardiography in the 2 groups: 1) tricuspid flow on inspiration and expiration-E wave, A wave, E/A ratio, deceleration time of the $\mathrm{E}$ wave; 2) pulmonary flow - the presence of anterograde diastolic flow. The mean of 3 measurements in each phase of the respiratory cycle was considered for analysis.

Comparison between the groups provided 2 subgroups: with and without impairment of right ventricular diastolic function.

The following variables were compared between the 2 groups: clinical variables (patient's age at the time of surgical repair and duration of the postoperative follow-up), surgical variables (duration of extracorporeal circulation, duration of aortic occlusion, duration of total circulatory arrest, minimum nasopharyngeal and rectal temperatures, duration of surgery), radiographic variables (cardiothoracic rate), and electrocardiographic variables (heart rate, PR interval, QRS duration, and cardiac rhythm).

The continuous variables were presented as mean and standard deviation. The Student $t$ test or the Mann-Whitney test, or both, and the chi-square test were used for comparison between the groups. Data were computed and analyzed with the $6.04 \mathrm{~b}$ version of the epidemiological EPIINFO software. The values were considered statistically significant when $\mathrm{p}<0.05$.

\section{Results}

The demographic data were similar for both groups (tab. I).

Tricuspid regurgitation was observed in 22 patients, being mild in $18(81.8 \%)$ patients and moderate in $4(18.2 \%)$. Mild pulmonary regurgitation was observed in 28 (93.3\%) patients and moderate pulmonary regurgitation in $2(6.7 \%)$.

Comparing the variables on Doppler echocardiogra-

\begin{tabular}{|c|c|c|c|}
\hline Variable & $\begin{array}{l}\text { Group I }(\mathrm{n}=30) \\
\text { Mean } \pm \mathrm{SD}\end{array}$ & $\begin{array}{l}\text { Group II }(n=30) \\
\text { Mean } \pm S D\end{array}$ & $\mathrm{P}$ \\
\hline Age (months) & $113.3 \pm 47.7$ & $98.4 \pm 43.6$ & 0.21 \\
\hline Weight (kg) & $28.9 \pm 13.7$ & $28.1 \pm 12.6$ & 0.80 \\
\hline Height $(\mathrm{cm})$ & $125.4 \pm 32.4$ & $127.3 \pm 20.4$ & 0.85 \\
\hline $\mathrm{BS}\left(\mathrm{m}^{2}\right)$ & $1 \pm 0.3$ & $1 \pm 0.2$ & 0.94 \\
\hline $\operatorname{Sex}(M / F)$ & $14 / 16$ & $14 / 16$ & 1.00 \\
\hline
\end{tabular}

phy, the A wave and the E/A ratio, both in inspiration and expiration, showed significant differences between the groups (tab. II). A significant correlation between these variables in inspiration and expiration was observed, with $\mathrm{r}=$ $0.87(0.61<\mathrm{CI}<0.84)$ for A wave, and $\mathrm{r}=0.70(0.27<\mathrm{CI}<$ $0.66)$ for E/A ratio.

Patients with an E/A ratio in inspiration $\leq 1.30$ (group I $-19 / 30$ and group II $-5 / 30, p<0.001$ ), sensitivity of $80.7 \%$ and specificity of $73.5 \%$ predominated. Considering the 2 subgroups after this cut point, only the QRS complex duration on the electrocardiogram was significantly increased in patients whose $\mathrm{E} / \mathrm{A}$ ratio $<1.30, \mathrm{p}<0.01(\mathrm{E} / \mathrm{A} \leq 1.30=0.12 \pm$ 0.03 and $\mathrm{E} / \mathrm{A}>1.30=0.1 \pm 0.03$ ).

Final anterograde diastolic flow in the pulmonary artery was observed in $19(63.3 \%)$ patients, none of them belonged to the control group.

Of the clinical variables, only the postoperative follow-up time was significantly altered, being longer in patients with positive anterograde diastolic flow, $p<0.001$ (positive anterograde diastolic flow of $85.22 \pm 38.88$ and negative anterograde diastolic flow of $45.45 \pm 26.14$ ). Of the electrocardiographic variables, the QRS complex duration was longer in patients with positive anterograde diastolic flow, $\mathrm{p}<0.01$ (positive anterograde diastolic flow of $0.13 \pm 0.02$ and negative anterograde diastolic flow of $0.10 \pm 0.04)$. The surgical and radiological variables did not have a statistical difference.

In regard to the tricuspid valve variables, the velocity of the A wave and the E/A ratio were significantly different in the 2 subgroups (tab. III).

\begin{tabular}{|c|c|c|c|c|}
\hline \multicolumn{5}{|c|}{$\begin{array}{l}\text { Table II - Comparison of the variables of the tricuspid valve between } \\
\text { the } 2 \text { groups }\end{array}$} \\
\hline Variable & Cycle & $\begin{array}{c}\text { Group I }(\mathrm{n}=30) \\
\text { Mean } \pm \mathrm{SD}\end{array}$ & $\begin{array}{l}\text { Group II }(\mathrm{n}=30) \\
\text { Mean } \pm \text { SD }\end{array}$ & 0) \\
\hline \multirow[t]{2}{*}{ E wave $(\mathrm{cm} / \mathrm{s})$} & Inspiration & $82.4 \pm 19.6$ & $73.9 \pm 17.4$ & 0.08 \\
\hline & Expiration & $62.2 \pm 14.5$ & $60 \pm 10.1$ & 0.49 \\
\hline \multirow[t]{2}{*}{ A wave $(\mathrm{cm} / \mathrm{s})$} & Inspiration & $70.5 \pm 13.9$ & $49 \pm 11.1$ & $<0.0001$ \\
\hline & Expiration & $60.4 \pm 12.1$ & $41 \pm 8.5$ & $<0.0001$ \\
\hline \multirow[t]{2}{*}{$\mathrm{E} / \mathrm{A}$} & Inspiration & $1.2 \pm 0.3$ & $1.5 \pm 0.4$ & $<0.001$ \\
\hline & Expirationo & $1 \pm 0.2$ & $1.5 \pm 0.3$ & $<0.0001$ \\
\hline \multirow[t]{2}{*}{$\mathrm{DT}(\mathrm{s})$} & Inspiration & $0.2 \pm 0$ & $0.2 \pm 0$ & 0.54 \\
\hline & Expiration & $0.2 \pm 0$ & $0.2 \pm 0$ & 0.40 \\
\hline
\end{tabular}




\begin{tabular}{|c|c|c|c|c|}
\hline \multicolumn{5}{|c|}{$\begin{array}{l}\text { Table III - Comparison of the variables of the tricuspid valve between } \\
\text { the } 2 \text { subgroups, with and without restrictive ventricle. }\end{array}$} \\
\hline Variable & Cycle & $\begin{array}{l}\text { Subgroup I } \\
+\mathrm{ADF}(\mathrm{n}=19) \\
\text { Mean } \pm \mathrm{SD}\end{array}$ & $\begin{array}{l}\text { Subgroup II } \\
\text { ADF }(\mathrm{n}=11) \\
\text { Mean } \pm \text { SD }\end{array}$ & $\mathrm{P}$ \\
\hline \multirow[t]{2}{*}{ E wave $(\mathrm{cm} / \mathrm{s})$} & Inspiration & $83.7 \pm 18$ & $80.1 \pm 22.8$ & 0.63 \\
\hline & Expiration & $60.7 \pm 12.5$ & $64.6 \pm 17.8$ & 0.48 \\
\hline \multirow[t]{2}{*}{ A wave $(\mathrm{cm} / \mathrm{s})$} & Inspiration & $66.3 \pm 12.7$ & $77.9 \pm 13.2$ & $<0.05$ \\
\hline & Expiration & $57.8 \pm 11.7$ & $64.9 \pm 11.8$ & 0.12 \\
\hline \multirow[t]{2}{*}{$\mathrm{E} / \mathrm{A}$} & Inspiration & $1.3 \pm 0.3$ & $1 \pm 0.3$ & $<0.05$ \\
\hline & Expiration & $1.1 \pm \quad 0.2$ & $1 \pm 0.3$ & 0.60 \\
\hline \multirow[t]{2}{*}{ DT (s) } & Inspiration & $212.8 \pm 49.6$ & $204.8 \pm 58.7$ & 0.69 \\
\hline & Expiration & $200.9 \pm 44.8$ & $203.5 \pm 56.7$ & 0.89 \\
\hline \multicolumn{5}{|c|}{$\begin{array}{l}\text { + } \mathrm{ADF} \text { - anterograde diastolic flow in the pulmonary artery; - ADF - no } \\
\text { anterograde diastolic flow in the pulmonary artery; E/A - relation between } \\
\mathrm{E} \text { wave and A wave; DT - E-wave deceleration time. }\end{array}$} \\
\hline
\end{tabular}

\section{Discussion}

Alterations in right ventricular diastolic function were observed after total repair of tetralogy of Fallot.

According to Cullen et $\mathrm{al}^{2}$, the fundamental abnormality is right ventricular restrictive physiology, characterized, on Doppler echocardiography, by the presence of an anterograde diastolic pulmonary flow coinciding with atrial systole. Its prevalence in the literature ranges from 28 to $52 \%{ }^{3,6}$. In our study, with an intermediate postoperative follow-up, $63.3 \%$ of the patients had this alteration. The homogeneity of our sample, with the use of a transannular patch in all patients, may perhaps explain this high frequency. Some authors ${ }^{4,7}$ found a correlation between this technique and the appearance of anterograde diastolic flow in the pulmonary artery.

Several studies have correlated preoperative and operative factors with restrictive right ventricular physiology; however, as in our study, few relevant data were found ${ }^{1-9}$.

Restrictive right ventricular physiology may relate to a process of endomyocardial fibrosis intrinsic to the disease itself and intensified as time goes by ${ }^{10}$, to the ventriculotomy, and to the interposition of patches in the interventricular septum and in the infundibulum ${ }^{3,4,6}$. It also seems to be influenced by immaturity of the right ventricle, which adapts to the aggressions of extracorporeal circulation, cardioplegia, and hypothermia ${ }^{6,11,12}$.

Myocardial dysfunction related to age has been investigated by some authors. Munkhammar et $\mathrm{al}^{6}{ }^{6}$ reported that patients undergoing surgery later had restrictive right ventricular physiology more frequently. Gatzoulis et al ${ }^{3}$ found no correlation of this alteration with the postoperative time.

In that study, the postoperative follow-up duration was longer in patients with restrictive ventricle, but age at surgery showed no significant difference, although it was greater in patients with restrictive physiology (3.2 years) than in those with no restriction (2.3 years).

Even considering the significant surgical factors ${ }^{3,4,6,11,12}$ for determining ventricular restriction, this study, like others ${ }^{2-9}$, could not demonstrate that relation.

Unlike the studies cited ${ }^{3,4,11}$, in which patients with restrictive physiology had shorter QRS duration and a lower cardiothoracic ratio, in our study, longer QRS duration and normal cardiothoracic ratio were observed in patients with restrictive right ventricular physiology.

Gatzoulis et al ${ }^{11}$ correlated QRS widening and the presence of cardiomegaly with the degree of pulmonary insufficiency. They reported that the more severe the pulmonary insufficiency, the larger the right ventricular size, as well as QRS duration, suggesting that restrictive physiology in these patients plays a protective role on the right ventricle, not allowing it to increase its size.

The discordance with the studies in the literature may perhaps be explained by sample differences regarding age, the postoperative follow-up duration, the degree of pulmonary insufficiency, and the surgical technique.

The echocardiographic data of the patients in our study were compared with those of healthy children. The velocity of the $A$ wave and the integral time of velocity were significantly greater in group I, which, consequently, had a lower E/A ratio.

In studies carried out with adults ${ }^{13,14}$, abnormal patterns of left ventricular transvalvar flow were defined, such as pseudonormalization, which is a transition between abnormal relaxation and ventricular restriction, corresponding to a moderate stage of diastolic dysfunction. This situation usually occurs in patients with high final diastolic blood pressure, in whom the diastolic velocities are normal. The patients in this study, both in inspiration and expiration, may be classified in this category.

The lower velocity of the A wave and the greater E/A ratio in the restrictive group corroborate with the idea that the right ventricle is really restrictive, because, if the right ventricle is less compliant, it begins to loose its elasticity, increasing pressure inside it. The ventricular filling is, therefore, more rapid than normal, and, on Doppler, this is seen as a tendency towards greater velocity of the $\mathrm{E}$ wave. Even if atrial contraction is effective, the pressure generated by it is not able to overcome ventricular pressure, which results in a lower A-wave velocity.

In the study by Cullen et al ${ }^{2}$, the E-wave velocity and the E-wave deceleration time were significantly lower in patients with a restrictive physiology, both in inspiration and expiration, while the A-wave velocity showed no difference. The inequalities between that study and ours may be attributed to methodology and sampling.

In expiration, no difference was observed between the echocardiographic variables of patients with and without ventricular restriction, in contrast with the significant reduction in the A wave in patients with restrictive physiology during inspiration.

In conclusion, restrictive right ventricular physiology was present in most patients undergoing repair of tetralogy of Fallot with a transannular patch. It may be a transient phenomenon of incomplete adaptation of that ventricle to volume and pressure modifications. Postoperative followup and QRS duration seem to relate to restrictive right ventricular physiology. Further studies are required for a better understanding of these alterations. 


\section{References}

1. Redington AN, Oldershaw PJ, Shinebourne EA, Rigby ML. A new technique for the assessment of pulmonary regurgitation and its application to the assessment of right ventricular function before and after repair of tetralogy of Fallot. $\mathrm{Br}$ Heart J 1988; 60: 57-65.

2. Cullen S, Shore D, Redington AN. Characterization of right ventricular diastolic performance after complete repair of tetralogy of Fallot: restrictive phisiology predicts slow postoperative recovery. Circulation 1995; 91:1782-9.

3. Gatzoulis MA, Clark AL, Cullen S, Cullen S, Newman CG, Redington AN Right ventricular diastolic function 15 to 35 years after repair of tetralogy of Fallot: restrictive phisiology predicts superior exercise performance. Circulation 1995; 91: 1775-81.

4. Norgård G, Gatzoulis MA, Moraes F, Lincoln C, Shore DF, Shinebourne EA, Redington AN. Relationship between type of outflow tract repair and postoperative right ventricular diastolic physiology in tetralogy of Fallot: implication for long-term outcome. Circulation 1996; 94: 3276-80.

5. Jonsson H, Ivert T, Brodin L.A. Echocardographic findings in 83 patients 13 - 26 years after intracardiac repair of tetralogy of Fallot. Eur Heart J 1995; 16: 1255-63.

6. Munkhammar P, Cullen S, Jogi P, de Leval M, Elliot M, Norgard G. Early age at repair prevents restrictive right ventricular physiology after surgery for tetralogy of fallot. J Am Coll Cardiol 1998; 32: 1083-7.

7. Eroglu AG, Saraglu A, Saraglu T. Right ventricular diastolic function after repair of tetralogy of Fallot: relationship to the insertion of a "transanular" patch. Cardiol Young 1999; 9: 384-91.

8. Redington AN, Penny D, Rigby ML, Hayes A. Anterograde diastolic pulmonary arterial flow as a marker of right ventricular restriction after complete repair of pulmonary atresia with intact septum and critical pulmonary valvar stenosis. Cardiol Young 1992; 2: 382-6.

9. Chaturverdi RR, Shore DF, Lincoln C, et al. Acute right ventricular restrictive phisiology after repair of tetralogy of Fallot: Association with myocardial injury and oxidative stress. Circulation 1999; 100: 1540-7.

10. Hegarty A, Anderson RH, Deanfild JE. Myocardial fibrosis in tetralogy of Fallot: effect of surgery or part of natural history? Br Heart J 1996; 59: 123.

11. Gatzoulis MA, Till JA, Somerville J, Redington AN. Mechanoelectrical interaction in tetralogy of Fallot. QRS prolongation relates to right ventricular size and predicts malignant ventricular arrhytmias and sudden death. Circulation 1995; 92: 231-7.

12. Horneffer PJ, Zahka KG, Row AS, et al. Long-term results of total repair of tetralogy of Fallot in childhood. Ann Thorac Surg 1990; 50: 179-85.

13. Appleton CP, Hatle LK. The natural history of left ventricular filling abnormalities: assesment by two dimensional and Doppler echocardiography. Echocardiography 1992; 9: 437-57.

14. Oki T. State of the art: "Diastology" research 1998. J Med Invest 1998; 45: 9-25. 